\title{
Isolation of Auxotrophs of Penicillium chrysogenum and their Penicillin Yields
}

\author{
By K. D. MACDONALD, J. M. HUTCHINSON AND W. A. GILLETT \\ Microbiological Research Establishment, Porton, Salisbury, Wiltshire
}

(Received 18 June 1963)

\begin{abstract}
SUMMARY
As a preliminary to an investigation of the inheritance of penicillin productivity in Penicillium chrysogenum several strains were genetically labelled with nutritional deficiencies and mutant spore colours. Few auxotrophs of $\boldsymbol{P}$. chrysogenum retained the potential for penicillin yield of their parents. An analysis suggests that when loss of penicillin production occurred in an auxotroph it was most likely due to pleiotropic effects of the single mutation to auxotrophy.
\end{abstract}

\section{INTRODUCTION}

The discovery of the parasexual process in Aspergillus nidulans by Pontecorvo \& Roper (1952) and its later demonstration in the asexual mould Penicillium chrysogenum (Pontecorvo \& Sermonti, 1953, 1954) opened the way for genetical analysis in this organism. Theoretically it should now be possible in $\boldsymbol{P}$. chrysogenum to combine in one strain desirable genetical characteristics which were originally in separate parents. Efforts have already been made in this direction, notably by Sermonti (1959); he presented evidence that the inheritance of penicillin productivity was under nuclear control.

The labelling of strains with genetical markers is an essential preliminary to the rational use of parasexuality; mutants which can be used include those having nutritional and spore-colour markers. Their isolation in Penicillium notatum and $\boldsymbol{P}$. chrysogenum was first described by Bonner (1946) and Pontecorvo (1946, 1947). When Bonner (1947) examined about 400 monoauxotrophs for penicillin yield, he found that only about $4 \%$ were defective in penicillin production. This was not the experience of Sermonti (1957 a) who found that a larger proportion of auxotrophs showed a diminution in penicillin yield; among eight auxotrophs for which he gave detailed results, four were certainly inferior in penicillin production when compared with their parent strains. A preliminary examination of the genetical basis of penicillin-titre decrease among auxotrophs of $\boldsymbol{P}$. chrysogenum is reported in this paper. The results described are more in agreement with those of Sermonti.

\section{METHODS}

Organisms. The genealogy of the four parent strains employed is given in Fig. 1; for convenience these were allocated domestic codes as shown there. For further details of the lineage of the Wisconsin series of strains (those prefixed 'Wis') consult Backus \& Stauffer (1955) and Stauffer (1961).

Minimal medium agar (MM). This was Czapek-Dox medium as modified by Clutterbuck, Lovell \& Raistrick (1932) with the adjustment to $\mathrm{pH} 7$ and the addition of $2 \%$ agar (Sermonti, 1954). Its composition was as follows : $\mathrm{NaNO}_{3}, \mathbf{3}$.; 


\section{K. D. Macdonald, J. M. Hutchinson and W. A. Gillett}

$\mathrm{KCl}, 0.5$ g.; $\mathrm{MgSO}_{4} .7 \mathrm{H}_{2} \mathrm{O}, 0.5$ g.; $\mathrm{FeSO}_{4} .7 \mathrm{H}_{2} \mathrm{O}, 0.01$ g.; $\mathrm{KH}_{2} \mathrm{PO}_{4}, 1$ g.; glucose, $40 \mathrm{~g}$.; agar, $20 \mathrm{~g}$.; distilled water to 11 . It was autoclaved at $115^{\circ}$ for $10 \mathrm{~min}$.

Complete medium agar (CM). This was based on the complete medium described by Sermonti $(1957 b)$ with slight modifications. It contained $\mathrm{KCl}, 0.5 \mathrm{~g} . ; \mathrm{MgSO}_{4} .7 \mathrm{H}_{2} \mathrm{O}$, 0.5 g.; $\mathrm{FeSO}_{4} .7 \mathrm{H}_{2} \mathrm{O}$, 0.01 g.; $\mathrm{KH}_{2} \mathrm{PO}_{4}, 1$ g.; corn steep liquor (Brown \& Polson) $10 \mathrm{~g}$.; $3 \mathrm{ml}$. each of thymus and yeast nucleic acid hydrolysates (Pontecorvo et al. 1953); DL-methionine, 0.05 g.; phenylacetylethanolamine, 1 g.; sucrose, 30 g.; agar, $20 \mathrm{~g}$.; distilled water to 1 l. The medium was adjusted to $\mathrm{pH} 6$ and autoclaved at $115^{\circ}$ for $10 \mathrm{~min}$.

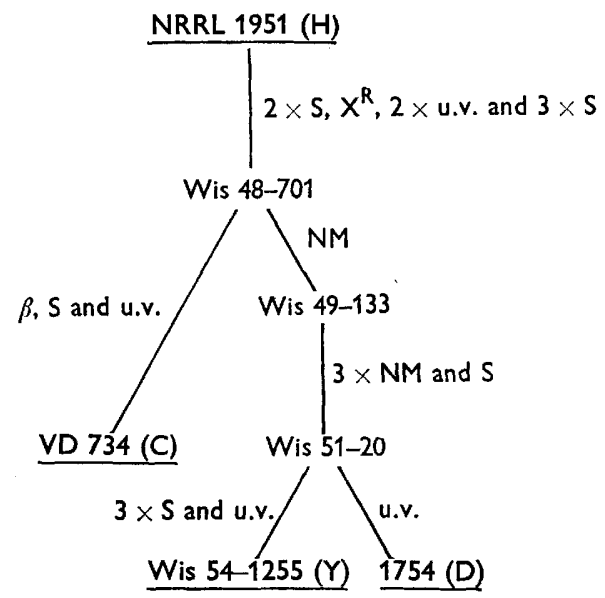

Fig. 1. Genealogy of strains of Penicillium chrysogenum. The strains underlined were used in the work which is described here; the domestic code of each of these is shown in brackets. $\mathbf{S}$ indicates selection without mutagenic treatment; $\mathbf{X}^{\mathbf{R}}$ indicates selection following X-ray treatment; $\beta$ indicates selection following $\beta$ irradiation; $\mathbf{u} . \mathbf{v}$. indicates selection following u.v irradiation; NM indicates selection following nitrogen mustard treatment. The number of selection steps is shown where applicable, e.g. u.v. = one u.v. treatment; $\mathbf{3} \times \mathbf{N M}=$ three successive $\mathbf{N M}$ treatments.

Mycelial development medium (M-unit medium). In this and the succeeding medium, corn-steep liquor (CSL) was added to a concentration determined by its total nitrogen content on a $\mathrm{w} / \mathrm{v}$ basis. The figures given indicate the final CSLnitrogen value in the media. M-unit medium had the following composition: brown sugar ('40' pieces, Tate and Lyle), 20 g.; $\mathrm{CaCO}_{3}, 10 \mathrm{~g}$.; phenylacetylethanolamine, $1 \mathrm{~g}$.; CSL-nitrogen, 3 g., distilled water to 1 l.; adjusted to $\mathrm{pH} 5.5$ with $40 \% \mathrm{KOH}$. The medium was distributed, while stirring, in $60 \mathrm{ml}$. amounts into $250 \mathrm{ml}$. Erlenmeyer flasks and $\mathbf{0} \cdot 14 \mathrm{ml}$. soya bean oil (Clyde Oil Refineries) was added to each flask, which were autoclaved at $120^{\circ}$ for 20 min. These flasks were termed M-units.

Fermentation medium (F-unit medium). This contained: lactose, 55 g.; $\mathrm{CaCO}_{3}$, 10 g.; $\mathrm{MgSO}_{4} .7 \mathrm{H}_{2} \mathrm{O}, 4.5$ g.; $\mathrm{KH}_{2} \mathrm{PO}_{4}, 7$ g.; phenylacetylethanolamine, $3.75 \mathrm{~g}$.; CSL-nitrogen about $2 \cdot 1 \mathrm{~g}$.; distilled water to $1 \mathrm{l}$. (The concentration of CSL can only be given approximately since the amount required for maximum penicillin production varied with the batch of CSL used.) The medium was adjusted to $\mathrm{pH} \mathbf{5 \cdot 2}$ with $40 \% \mathrm{KOH}$, and while being stirred the medium was distributed in $40 \mathrm{ml}$. amounts into $250 \mathrm{ml}$. Erlenmeyer flasks; to each flask was added $1.6 \mathrm{ml}$. of water- 
white mineral oil (Esso Petroleum Co.) and $0.33 \mathrm{ml}$. soya bean oil. Autoclaving was at $120^{\circ}$ for $15 \mathrm{~min}$. These flasks were termed F-units.

Incubation. Cultures grown on agar medium were incubated at $25^{\circ}$ and shake

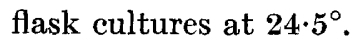

Production of mutants. These were isolated after ultraviolet (u.v.) irradiation. Ten $\mathrm{ml}$. of a dispersed suspension of conidia $\left(10^{6}\right.$ total conidia $/ \mathrm{ml}$.) were irradiated with a 'Hanovia' lamp, Type 11 with a 12 in. tube. The suspension in distilled water was contained in a $3 \frac{1}{2}$ in. diameter Petri dish, with lid removed, at a distance of $30 \mathrm{~cm}$. from the u.v. source and was mechanically rocked during treatment. The time of irradiation, usually 5-8 min., was adjusted so that the plating of conidia on CM agar showed a 1-5\% survival.

Di and triauxotrophs were produced by u.v. irradiation of mono and diauxotrophs respectively. Auxotrophs were selected by the 'total isolation' method (Fries, 1948) and characterized by techniques as described by Pontecorvo et al. (1953). Spore-colour mutants were isolated after visual inspection.

Nomenclature. (a) In this paper the system of abbreviations for nutritional mutants is similar to that of Demerec (1956; see also Microbial Genetics Bulletin, 1958, no. 16); they are shown in Table 1.

(b) Mutants obtained from the four parental strains, c, D, H and Y (see Fig. 1) were labelled $\mathrm{c} 1, \mathrm{c} 2$, etc.

Table 1. Abbreviations used for auxotrophs

$\begin{array}{lll}\text { bio }=\text { biotin } & \text { arg }=\text { arginine } & \text { phl }=\text { phenylalanine } \\ \text { cho }=\text { choline } & \text { cys }=\text { cysteine } & \text { pro }=\text { proline } \\ \text { ino }=\text { inositol } & \text { his }=\text { histidine } & \text { val }=\text { valine } \\ \text { nic }=\text { nicotinamide } & \text { leu }=\text { leucine } & \text { ade }=\text { adenine } \\ \text { pab }=p \text {-aminobenzoic acid } & \text { lys }=\text { lysine } & \text { thio }=\text { thiosulphate* } \\ \text { pdx }=\text { pyridoxin } & \text { met }=\text { methionine } & \text { amo }=\text { ammonium } \dagger \\ \text { thi }=\text { thiamine } & & \end{array}$

* These auxotrophs required a more reduced form of inorganic sulphur than is present in minimal medium (MM). To allow their growth MM was supplemented with $\mathrm{Na}_{2} \mathrm{~S}_{2} \mathrm{O}_{3}$.

$\dagger$ These auxotrophs required a more reduced form of inorganic nitrogen than is present in MM. To allow their growth $\mathrm{MM}$ was supplemented with $\left(\mathrm{NH}_{4}\right)_{2} \mathrm{SO}_{4}$.

Culture maintenance. Cultures were maintained initially on CM agar slopes in $1 \mathrm{oz}$, narrow-necked McCartney bottles with screw caps. Cultures for long-term storage were dried by a modification of the method devised by Stamp (1947) and stored at $4^{\circ}$ in vacuo over silica gel.

Rotary shaker. This was of the type described by Paladino (1954). The design was modified slightly and the tray built to hold 144 Erlenmeyer flasks of $250 \mathrm{ml}$. capacity. The shaker had a 2 in. throw and ran at $220 \mathrm{rev} . / \mathrm{min}$. It was enclosed in a cabinet maintained internally at $24 \cdot 5^{\circ}$.

Penicillin yield testing. Ten ml. $0.02 \%(\mathrm{v} / \mathrm{v})$ ' calsolene' oil (I.C.I. Ltd.) in distilled water was added to a slope culture and the conidia and mycelium suspended therein. The suspension was removed and shaken with glass beads then $2 \mathrm{ml}$. were inoculated into an M-unit and incubated on the shaker for $48 \mathrm{hr}$. One $\mathrm{ml}$. of the resulting mycelial suspension was transferred to an F-unit, incubated on the shaker for 6 days and then assayed. 


\section{K. D. Macdonald, J. M. Hutchinson and W. A. Gillett}

Penicillin assays. Liquid cultures were filtered through Whatman no. 1 paper and the filtrate used for assay. Two methods were used. One was a simplification of the hydroxylamine method as detailed by Carta-De Angelis, Ventura \& Dentice de Accadia (1959). This chemical method was suitable with strains C, D and $\mathrm{Y}$ and mutants derived from them. However strain $\mathrm{H}$ exuded a yellow pigment (Clutterbuck et al. 1932) which interfered with colorimetric determinations. A biological assay was therefore used for strain $\mathrm{H}$ and its derivatives (Humphrey \& Lightbown, 1952). Assay results were expressed in units of penicillin $/ \mathrm{ml}$.

\section{RESULTS}

Auxotrophs occurred with a frequency of about 0.5\%. About $40 \%$ showed slight growth on minimal medium agar when tested by the auxanographic method (Pontecorvo, 1949) and may be of the 'leaky' variety as described by Bonner, Yanofsky \& Partridge (1952). Each nutritional mutant selected after a single mutagenic treatment had one more growth factor deficiency than its parent, except strain D21 which acquired, in addition to the mutation present in its immediate parent, requirements for thiamine + pyridoxin. It is not known whether this change was due to a single or double mutational event. The relative frequencies of auxotrophs derived after mutagenic treatment of prototrophic parents were similar to those published by Bonner (1946) for Penicillium chrysogenum.

Penicillin titres of mutants are shown in the tables as fractions of those of their parental strains (c, D, H or $\mathrm{Y}$ ) determined in the same experiments; these fractions were termed 'yield indices'. The penicillin yield of each mutant was estimated from the average of at least two replicates; over numerous replicates the parents averaged approximately: c, $3000 \mathrm{u} . / \mathrm{ml}$; ;, $4000 \mathrm{u} . / \mathrm{ml}$; н, $150 \mathrm{u} . / \mathrm{ml}$.; $\mathrm{y}, \mathbf{3 5 0 0} \mathrm{u} . / \mathrm{ml}$.

Auxotrophs derived from each of the prototrophic parents after a single u.v. treatment are shown in Table 2 where it can be seen that many have low yield indices.

Table 2. Distributions of penicillin yields among auxotrophs with single growth factor requirements derived from strains $\mathrm{c}, \mathrm{D}, \mathrm{H}$ and $\mathrm{Y}$

The yield index of a mutant is its performance shown as a fraction of the penicillin titre of its parental strain (c, $D, H$ or $\mathbf{Y})$.

\begin{tabular}{|c|c|c|c|c|c|c|c|}
\hline \multirow{3}{*}{$\begin{array}{l}\text { Growth } \\
\text { factor } \\
\text { require- } \\
\text { ment of } \\
\text { auxo- } \\
\text { troph }\end{array}$} & \multicolumn{7}{|c|}{ No. of auxotrophs } \\
\hline & \multirow[b]{2}{*}{ Total } & \multicolumn{6}{|c|}{ Yield index groups } \\
\hline & & $1 \cdot 25-1 \cdot 00$ & $0.99-0.76$ & $0.75-0.51$ & $0.50-0.26$ & $0.25-0.01$ & o \\
\hline bio & 3 & 1 & 2 & . & . & . & . \\
\hline cho & 1 & . & . & . & . & 1 & . \\
\hline nic & 1 & . & . & . & . & 1 & . \\
\hline thi & 5 & 2 & 1 & 1 & 1 & . & - \\
\hline $\arg$ & 1 & . & . & . & . & 1 & . \\
\hline his & 3 & . & . & 1 & 1 & . & $\mathbf{1}$ \\
\hline leu & 2 & . & . & . & . & 2 & . \\
\hline lys & 2 & . & . & . & 1 & 1 & . \\
\hline met & 5 & . & 1 & 2 & . & 2 & . \\
\hline ade & 1 & . & . & . & . & $\mathbf{1}$ & . \\
\hline thio & 3 & . & . & . & 2 & 1 & . \\
\hline amo & 3 & - & 2 & 1 & . & - & - \\
\hline Totals & 30 & 3 & 6 & 5 & 5 & 10 & 1 \\
\hline$\%$ & 100 & 10 & 20 & $16 \cdot 7$ & $16 \cdot 7$ & $\mathbf{3 3 \cdot 3}$ & $3 \cdot \mathbf{2}$ \\
\hline
\end{tabular}


The decrease in penicillin titre which may accompany a nutritional mutation, might be due to a pleiotropic effect of the gene change from prototrophy to auxotrophy or be the result of an additional mutational event. A decision between these alternative explanations might be facilitated by a comparison of the penicillin yields of mutants with those of a random sample of single colonies originating from conidia which survived a u.v. treatment similar to that used in the derivation of mutants. As a control for the results given in Table 2, since it was believed that strains $\mathrm{C}, \mathrm{D}, \mathrm{H}$ and $\mathrm{Y}$ would not differ in their behaviour, strain $\mathrm{C}$ was selected and

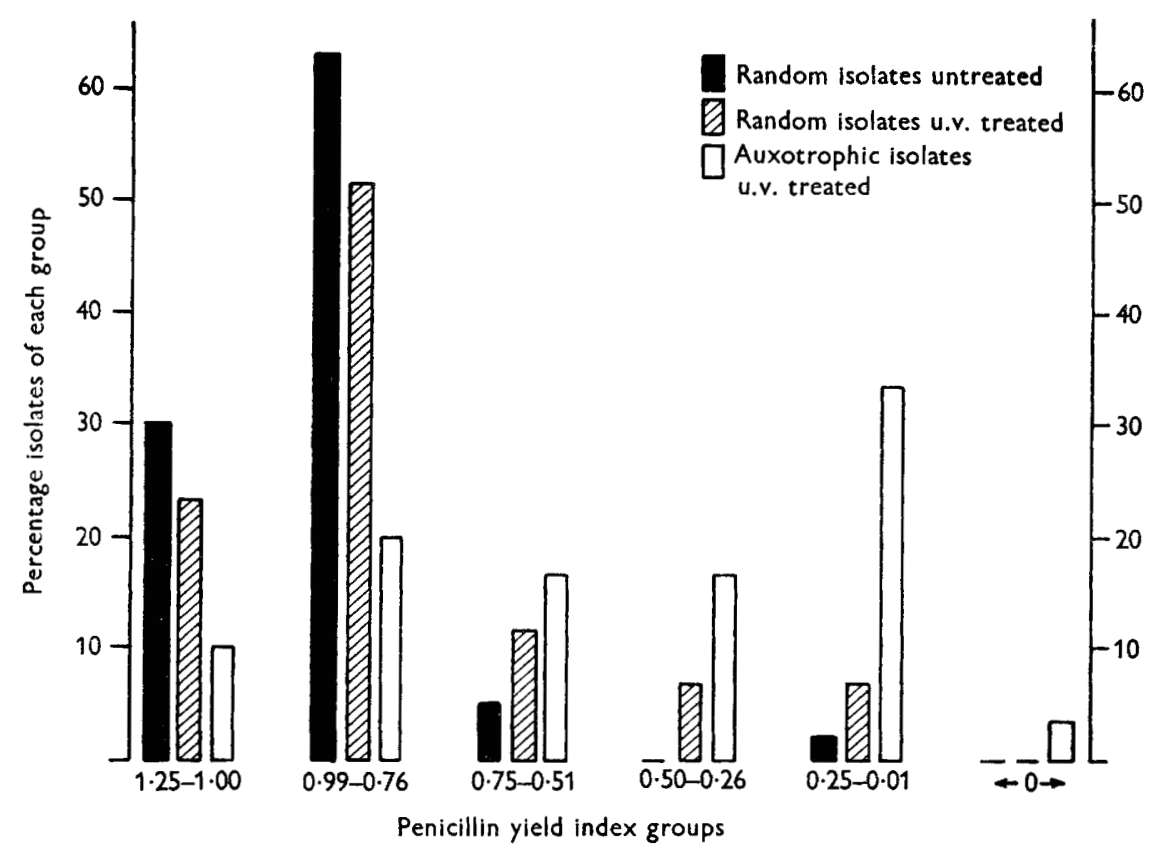

Fig. 2. Distributions of penicillin yields among: (1) Single colony isolates grown from conidia of strain c (100). (2) Single colony isolates grown from conidia of strain $\mathrm{c}$ which survived a u.v. dosage similar to that used in the derivation of auxotrophs (103). (3) Auxotrophs with single growth factor requirements isolated after u.v. treatment of conidia from parental strains $\mathrm{C}, \mathrm{D}, \mathrm{H}$ and $\mathrm{Y}(30)$. The total number in each group is shown in parentheses.

isolates were made on to complete medium agar (CM) of a random selection of colonies which arose from the plating of conidia of this strain on CM agar. Random isolates were also made of colonies of strain $\mathrm{c}$ which grew from conidia which had survived a u.v. treatment of similar dosage to that used in the derivation of auxotrophs. Each single colony isolate was tested for penicillin yield in one F-unit (Table 3). The distributions of penicillin yields among auxotrophs from Table 2 and single colony isolates from Table 3 are illustrated in Fig. 2. Unfortunately it is not possible to assess the effects of spore colour mutations on penicillin yield since insufficient were isolated.

Another possible method of investigating whether the decrease in penicillin yield which occurs in mutants is a pleiotropic or a double-mutational effect involves searching among auxotrophs for mutants which have returned to the prototrophic 


\section{K. D. Macdonald, J. M. Hutchinson and W. A. Gillett}

Table 3. Distributions of penicillin yields among single colony isolates grown from conidia of strain $\mathrm{c}$ and of similar isolates grown from conidia of strain $\mathrm{c}$ which survived a u.v. dosage similar to that used in the derivation of nutritional and spore colour mutants

The yield index of strain $\mathrm{c}$ was taken as unity and the penicillin performance of individual colonies was related to this.

$\overbrace{\text { Total } \overbrace{1.25-1.00}^{\text {Yield index groups }} \quad \text { Single colony isolates }}^{\text {Y.9.76 } \quad \overbrace{0.75-0.51 \quad 0.50-0.26 \quad 0.25-0.01}}$

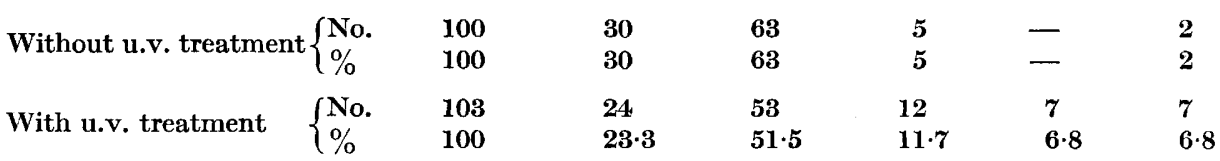

condition. If pleiotropy applied, a mutation which restored prototrophy might also restore penicillin yield, whereas if a second mutation were involved prototrophic isolates would be expected to retain the yield of their auxotrophic parent. This is assuming that mutations occur independently and at a low rate.

Tests of these alternatives were made with strain $\mathbf{c} 13$ derived as follows:

\author{
Strain \\ Spore colour \\ Growth factor requirement(s)
}

Yield index

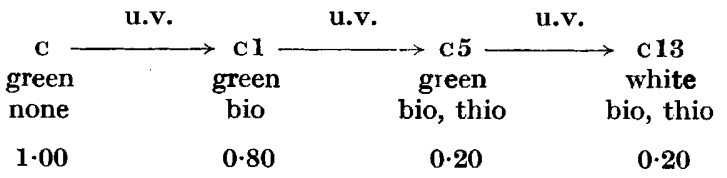

The introduction of the thio marker was accompanied by a substantial decrease in penicillin yield. Mutation to the loss of this requirement was examined in strain $\mathrm{c} 13$, in preference to strain $\mathrm{c} 5$ since the mutant spore-colour was a useful additional marker for the recognition of derivatives and did not appear to affect penicillin titre. Conidia were spread at $10^{6}$ viable units on each of several plates containing MM agar supplemented with biotin only. After 14 days of incubation, 11 whitespored cultures were isolated, each having a growth factor requirement for biotin only. They occurred at an approximate frequency of 1 in $10^{7}$ viable spores. When tested for penicillin yields, 5 had the titre value of $\mathrm{c} 1$ strain and 6 of $\mathrm{c} 13$ strain. Thirty-six single-colony isolates of $\mathrm{c} 13$ strain were made subsequent to the plating of dispersed conidia on CM agar and these isolates were yield tested. All had the titre of $\mathrm{c} 13$ strain; this was taken as showing that $\mathrm{c} 13$ strain was not a mixture of high and low yielding types and that the occurrence of high and low yielding 'revertants' from c13 strain could not be explained on this basis.

The distributions of penicillin yields among nutritional mutants in relation to specific growth factor requirements are shown in Table 4.

\section{DISCUSSION}

Among auxotrophs there is a distinct bias towards low penicillin titre in comparison with controls of random isolates (Fig. 2). If the diminution in titre among auxotrophs were always due to additional mutational events, a sample of auxo- 
trophs would be expected to show a similar titre distribution to that of a random sample of isolates after the same mutagenic treatment, provided mutations occurred at random. The results suggest therefore that the diminution in penicillin yield

\section{Table 4. Distribution of penicillin yields among auxotrophs in relation to specific growth factor requirements}

Auxotrophs shown here include those derived from the original parent strains (c, D, $\mathbf{H}$ and $\mathrm{y}$ ) and from spore-colour and auxotrophic mutants originating from these parent strains. Auxotrophs from mutant parents were included only if the latter had titre levels similar or close to those of the original prototrophic parents. Yield indices were calculated relative to the penicillin yield of the original parental strains which were taken as unity.

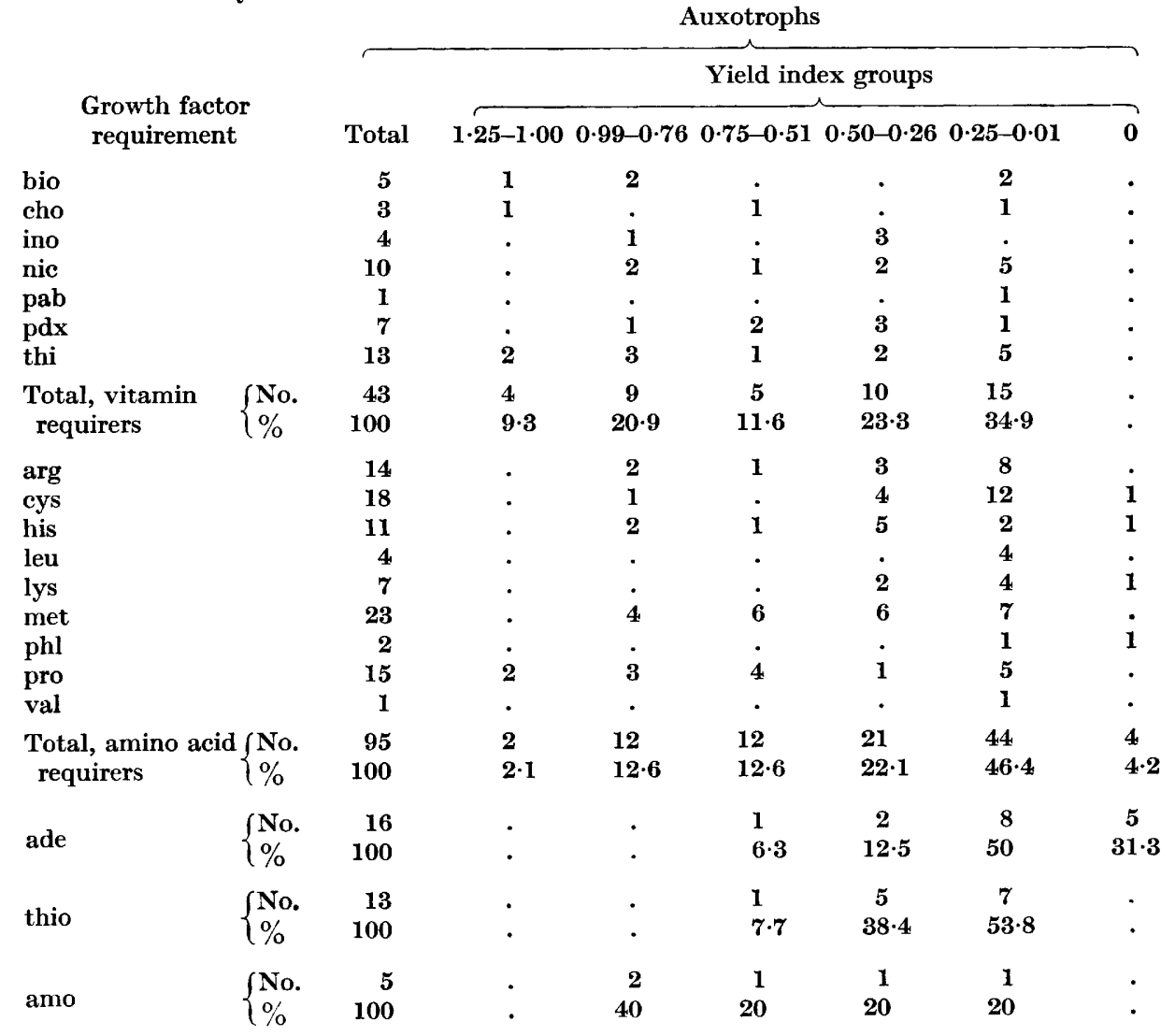

found among certain auxotrophs was most likely to be due to pleiotropic effects of the auxotrophic locus, although it cannot unequivocally be stated in any one case that pleiotropy is operative and that decrease of yield is not due to a second mutation. When random isolates were made of colonies developed from conidia surviving u.v. treatment, more than $10 \%$ had titre values decreased to below half that of the parent strain (Table 3, Fig. 2). This implies that among a sample of auxotrophs, even if pleiotropy be accepted as the main cause of titre decrease, there may be a small proportion which have a low penicillin yield for reasons other than the pleiotropic effects of auxotrophic mutation. 


\section{K. D. Macdonald, J. M. Hutchinson and W. A. Gillett}

The loss of a growth factor requirement is possible after reverse or suppressor mutation (see Catcheside, 1950). Suppressor mutations can vary in their specificity. Some will suppress a growth factor requirement resulting from mutations at different loci; others are specific for a single locus (Pontecorvo, 1959). It is perhaps not unreasonable to suggest that certain suppressors are specific for only some of the pleiotropic effects of a single locus. In the experiment with strain c13 it is feasible that among strains which had regained independence of thio, those which were still low in penicillin yield had suppressors which did not affect titre restoration, while those which showed increased yield had suppressors which eliminated the pleiotropic effect on yield or were strains having a reverse mutation at the genetic site of auxotrophy. It is suggested therefore that the method employed with strain $\mathrm{c}$ 13, although laborious, offers a means of discovering whether pleiotropy is operative in any specific case.

There is clearly no close correlation between specific growth factor requirement and penicillin titre, although certain types of auxotrophs, e.g. those requiring adenine, tend to be low in titre (Table 4). Auxotrophs with the same growth factor requirement could result from mutations at different genetic loci, and if these different mutations exhibited dissimilar pleiotropic effects, they might affect penicillin yield in different ways. As a corollary, it might be possible to group mutants, having the same growth factor requirement, with respect to their penicillin yield and to anticipate that those which have similar titre values would have a greater degree of genotypic similarity. When auxotrophs are collected into broad groups and these examined for their titre distributions (Table 4), vitamin requirers tend to be higher in titre value than amino acid requirers, which in turn are higher than adenine requirers. The ramifications of pleiotropy (including interference with penicillin production) which followed a mutation giving rise to a more fundamental block in cell metabolism, such as resulted from an adenine deficiency, might be greater than the more limited pleiotropic effects which might be expected to follow a mutation which involved a less fundamental (though nevertheless essential) process, e.g. mutation to a particular vitamin deficiency.

Alikhanian et al. (1959) showed that the low antibiotic yield of certain auxotrophs of Streptomyces rimosus was increased by adding more of the specific growth factor than was needed for growth. With four adenineless and three lysineless auxotrophs of our series of mutants, the addition of extra amounts of growth factors did not affect penicillin yield except in one case. Here the addition of lysine doubled penicillin yield, although this increase was only to $50 \%$ of the yield of the mutant's immediate parent. Following mutation to increased yield of penicillin it is often necessary to change the environment to gain optimum conditions of production (Arnstein \& Grant, 1956). A similar situation might exist following auxotrophic mutation, in that the conditions for maximum production by the mutant might differ from those for the parent. If titre were diminished, experimental manipulation of the environment more involved than that described above might restore penicillin yield.

Special gratitude is due to Dr D. W. Henderson, F.R.S., for his constant encouragement and we are very much indebted to Professor J. A. Roper and Dr T. W. Burrows for discussion and advice. We are grateful to Mr R. Elsworth who designed 
the shaker cabinet and to Mr G. H. Clement who was responsible for modifying and constructing the rotary shaker. We also wish to thank Mr E. W. Harris for his expert technical assistance. Grateful acknowledgement is paid to Boots Pure Drug Co. Ltd., The Distillers Co. Ltd., Glaxo Laboratories Ltd. and Imperial Chemical Industries Ltd. who between them supplied strains of Penicillium chrysogenum, methods of penicillin fermentation, corn-steep liquor and other materials. Our thanks are also extended to Professors M. P. Backus and J. F. Stauffer for the gift of the Wisconsin series of $P$. chrysogenum strains. This work was financed by the National Research Development Corporation.

\section{REFERENCES}

Alikhanian, S. I., Mindlin, S. Z., Goldat, S. U. \& Vladimizov, A. V. (1959). Genetics of organisms producing tetracyclines. Ann. N.Y. Acad. Sci. 81, 914.

Arnstein, H. R. V. \& Grant, P. T. (1956). The metabolism of penicillia in relation to penicillin biosynthesis. Bact. Rev. $20,133$.

Backus, M. P. \& Stauffer, J. F. (1955). The production and selection of a family of strains in Penicillium chrysogenum. Mycologia, 47, 429.

Bonner, D. (1946). Production of biochemical mutations in Penicillium. Amer. J. Bot. 33, 788.

Bonner, D. (1947). Studies on the biosynthesis of penicillin. Arch. Biochem. $13,1$.

Bonner, D. M., Yanofsky, C. \& Partridge, C. W. H. (1952). Incomplete genetic blocks in biochemical mutants of Neurospora. Proc. nat. Acad. Sci., Wash. 38, 25.

Carta de Angelis, L., Ventura, M. T. \& Dentice Di Accadia, F. (1959). Simplification of the hydroxylamine colorimetric method for penicillin determination in fermentation media and finished salts. Sel. Sci. Pap. Ist. sup. Sanit. 2, 99.

Catcheside, D. G. (1950). Gene action and mutation. Riochem. Soc. Symp. 4, 32.

Clutterbuck, P. W., Lovell, R. \& Raistrick, H. (1932). cexxvii. Studies on the biochemistry of micro-organisms. xxvi. The formation from glucose by members of the Penicillium chrysogenum series of a pigment, an alkali-soluble protein and penicillin the antibacterial substance of Fleming. Biochem. J. 26, 1907.

Demerec, M. (1956). Terminology and nomenclature. Genetic studies with bacteria. Publ. Carneg. Instn, no. 612, 1.

Fries, N. (1948). Viability and resistance of spontaneous mutations in Ophiostoma representing different degrees of heterotrophy. Physiol. Plant. 1, 330.

Humphrey, J. H. \& LightBown, J. W. (1952). A general theory of plate assays of antibiotics with some practical applications. J. gen. Microbiol. 7, 129.

Paladino, G. (1954). A simple rotary shaker. R.C. Ist. sup. Sanit. (English edition), $17,145$.

Ponteconvo, G. (1946). Genetic systems based on heterokaryosis. Cold Spr. Harb. Symp. quant. Biol. 11, 193.

Ponteconvo, G. (1947). The genetical control of nutritional requirements in micro-organisms and its application to microbiological assays. Proc. Nutr. Soc. 5, 182.

Ponteconvo, G. (1949). Auxanographic techniques in biochemical genetics. J. gen. Microbiol. 3, 122.

Ponteconvo, G. (1959). Trends in Genetic Analysis, 1st ed. London: Oxford University Press.

Ponteconvo, G. \& Roper, J. A. (1952). Genetical analysis without sexual reproduction by means of polyploidy in Aspergillus nidulans. J. gen. Microbiol. 6, vii.

Pontecorvo, G., Roper, J. A., Hemmons, L. M., Macdonald, K. D. \& Bufton, A. W. J. (1953). The genetics of Aspergillus nidulans. Advanc. Genet. 5, 141.

Pontecorvo, G. \& Sermonti, G. (1953). Recombination without sexual reproduction in Penicillium chrysogenum. Nature, Lond. 172, 126. 


\section{K. D. Macdonald, J. M. Hutchinson and W. A. GrLlett}

Ponteconvo, G. \& Sermonti, G. (1954). Parasexual recombination in Penicillium chrysogenum. J. gen. Microbiol. 11, 94.

Sermonti, G. (1954). Genetics of Penicillium chrysogenum. 1. Heterokaryosis in Penicillium chrysogenum. R.C. Ist. sup. Sanit. (English edition), 17, 213.

Sermonti, G. (1957a). Produzione di penicillina da diploidi Penicillium chrysogenum. Conv. Genetica Alti 3 Riunione, A.G.I. Suppl. Ricerca Sci. 27, 3.

Sermontr, G. $(1957 b)$. Analysis of vegetative segregation and recombination in Penicillium chrysogenum. Genetics, 42, 433.

Sermontr, G. (1959). Genetics of penicillin production. Ann. N.Y. Acad. Sci. 81, 950.

Stamp, Lond (1947). The preservation of bacteria by drying. J. gen. Microbiol. 1, 251.

StaufFer, J. F. (1961). The use of ultra violet radiation for mutation in antibiotic producing fungi. Sci. Rep. Ist. sup. Sanit. 1, 472. 